Community Well-Being among the Registered Indian and non-Aboriginal populations in Winnipeg: Trends over time and spatial analysis

Evelyne Bougie (1), Dafna Kohen (1), Chris Penney (2), Sacha Senécal (2,3), and Eric Guimond $(2,3)$

(1) Health Analysis Division, Statistics Canada

(2) Strategic Research Directorate, Aboriginal Affairs and Northern Development

(3) University of Western Ontario

aboriginal policy studies Vol. 4, no. 1, 2015, pp. 24-45

This article can be found at:

http://ejournals.library.ualberta.ca/index.php/aps/article/view/21037

ISSN: $1923-3299$

Article DOI: http://dx.doi.org/10.5663/aps.v4i1.21037

aboriginal policy studies is an online, peer-reviewed and multidisciplinary journal that publishes original, scholarly, and policy-relevant research on issues relevant to Métis, non-status Indians and urban Aboriginal people in Canada. For more information, please contact us at apsjournal@ualberta.ca or visit our website at www.ualberta.ca/nativestudies/aps/. 


\section{Community Well-Being among the Registered Indian and non-Aboriginal populations in Winnipeg: Trends over time and spatial analysis ${ }^{1}$}

Evelyne Bougie $^{2}$ (1), Dafna Kohen (1), Chris Penney (2), Sacha Senécal (2,3), and Eric Guimond $(2,3)$

(1) Health Analysis Division, Statistics Canada

(2) Strategic Research Directorate, Aboriginal Affairs and Northern Development

(3) University of Western Ontario

Abstract: The CWB Index has been developed to investigate well-being at the community level using census subdivisions to define the different types of communities. Because the basis for analysis is the entire population of a community, the presence of non-Aboriginal populations living in First Nations or Inuit communities, or of Aboriginal people living in "other" (nonAboriginal) communities, has not yet been considered. Therefore, to date, the differences in well-being between Aboriginal and non-Aboriginal residents of the same areas have not been investigated at the community level. In addition, few (if any) CSDs identified as First Nations or Inuit are located in urban areas. There is a need to understand better the well-being of this segment of Canada's population (Newhouse and Peters 2003). Thus the purpose of the present study was to apply the CWB Index to describe the socioeconomic well-being of Aboriginal and non-Aboriginal residents of the same urban centers. For this purpose, we use the city of Winnipeg in Manitoba, Canada as a "case study" because of its large Aboriginal population.

\section{Introduction}

Many population-based composite measures have been developed to monitor the wellbeing of the Canadian population (e.g., the Canadian Index of Wellbeing [CIW 2012]; the Canadian Marginalization Index [Matheson et al. 2012]; the Deprivation Index [Pampalon et al. 2012]; the Socio-Economic Factor Index [Chateau et al. 2012]; and the Vancouver Area Neighbourhood Deprivation Index [Bell and Hayes 2012]). Generally speaking, composite measures seek to combine several socioeconomic and socio-demographic factors into a single "well-being" index. Well-being indices are important population monitoring tools that can guide service delivery and resource allocation, as well as help inform policies and programs aimed at improving population well-being.

1 Disclaimer: This paper was funded by the Strategic Research Directorate at Aboriginal Affairs and Northern Development (AANDC). The views expressed in this document are those of the authors and do not necessarily represent the position of Statistics Canada or AANDC.

2 Corresponding author: Evelyne Bougie, Health Analysis Division, Statistics Canada, R.H. Coats Building Floor 24 D, 100 Tunney's Pasture Driveway, Ottawa, ON, K1A 0T6. Email: Evelyne.Bougie@statcan.gc.ca. Telephone: 613-951-4765 / Facsimile: 613-951-3959.

aboriginal policy studies, vol. 4, no. 1, 2015 
The Community Well-Being (CWB) Index, developed by Aboriginal Affairs and Northern Development Canada (AANDC) (see O'Sullivan 2011), is the only national measure that has been created specifically to investigate the socioeconomic well-being of First Nations, Métis, and Inuit communities in Canada. So far, research using the CWB Index has focused mostly on comparing communities, defined on the basis of census subdivisions (or municipalities). The present study introduces an application of the CWB Index aimed at comparing the socioeconomic well-being of Registered Indian and nonAboriginal residents of the same census tracts (a proxy for neighbourhoods), focusing on Winnipeg as a "case study" due to its large Aboriginal population. We start by briefly describing the CWB Index and summarizing key past research findings.

\section{The Community Well-Being (CWB) Index}

The CWB Index uses Statistics Canada's Census of Population to produce a socioeconomic (or CWB) score. This score is based on seven indicators, combined into four "well-being" components: education (high school and university graduation rates), housing quality (whether major repairs are required) and quantity (crowding), labour-force activity (participation and employment), and income. The CWB Index provides a systematic and reliable summary measure of socioeconomic well-being for nearly all Canadian communities; illustrates variations in well-being across First Nations, Métis, and Inuit communities and how it compares to that of other Canadian communities; and allows for well-being to be tracked over time (see White et al. 2007 and O'Sullivan 2011 for a detailed description of the CWB).

The CWB Index has been developed and used most often by aggregating individuallevel data at the geographic level of census subdivisions (CSDs), ${ }^{3}$ irrespective of residents' ethnocultural affiliations. Thus, Indian reserves or settlements can be classified as "First Nations" communities; CSDs located within any of the four Inuit regions can be classified as "Inuit" communities; CSDs with important Métis populations can be classified as "Métis" communities; and all other CSDs can be classified as "other" Canadian communities. CWB scores in these different types of communities can then be compared.

Key research findings using the CWB Index have illustrated the well-known disparities in socioeconomic well-being between Aboriginal and non-Aboriginal communities. Indeed, while average CWB scores for First Nations and non-Aboriginal communities increased between 1981 and 2006, First Nations communities had lower average CWB scores and component scores than non-Aboriginal communities in all years investigated (1981 to 2006) (O'Sullivan 2011). Similar patterns have been observed regarding the wellbeing of Inuit communities; that is, despite improvements in CWB scores over time (1991 to 2001), overall scores in Inuit communities were still lower when compared to other Canadian communities (Senécal et al. 2007). The CWB of Métis communities have also been documented. Métis communities typically display higher levels of well-being than Inuit and First Nations communities, but lower levels than non-Aboriginal communities (LaPointe et al. 2009).

$3 \mathrm{~A} \mathrm{CSD}$ is a municipality or an area that is deemed to be equivalent to a municipality for statistical reporting purposes. 
In terms of regional analyses, First Nations communities located in the Prairies have been shown to have lower average CWB than First Nations in other regions. The Prairies also stood out as the region where gaps in well-being between First Nations and nonAboriginal communities were the largest and where First Nations communities improved the least over time (O'Sullivan 2011).

\section{Purpose of the Present Study}

The CWB Index was originally developed to investigate well-being at the community level using census subdivisions (or municipalities) to define the different types of communities. Because the basis for analysis is the entire population of a community, the presence of non-Aboriginal populations living in First Nations or Inuit communities, or of Aboriginal people living in "other" (non-Aboriginal) communities, has mostly been overlooked. In addition, few (if any) CSDs identified as First Nations or Inuit are located in urban areas. There is a need to understand better the well-being of this segment of Canada's population (Newhouse and Peters 2003).

One exception to this omission is Clatworthy and Peters (2011), who have compared CWB scores of Aboriginal and non-Aboriginal residents of the same friendship centre catchment areas. ${ }^{4}$ To date, however, the differences in CWB scores between Aboriginal and non-Aboriginal residents of the same urban areas remain largely unexplored, especially for specific Aboriginal groups and at more granular geographic levels such as neighbourhoods or neighbourhood clusters. The purpose of the present study was therefore to introduce an application of the CWB Index to describe the socioeconomic well-being of Aboriginal and non-Aboriginal residents of the same urban centres at the census-tract level of analysis, and to pair this analysis with spatial data. For this purpose, we use the city of Winnipeg in Manitoba, Canada as a "case study" because of its large Aboriginal population.

\section{Winnipeg: A Large, Young, and Growing Aboriginal Population}

The city of Winnipeg has many distinctive features that make it particularly interesting to focus on as a case study of Aboriginal and non-Aboriginal urban well-being. In 2006, Winnipeg was the census metropolitan area (CMA) with the largest Aboriginal population of any city in Canada, with 68,385 Aboriginal people - about 10 percent of the city's total population. In comparison, the CMAs of Edmonton and Vancouver had the second- and third-largest number of Aboriginal people among Canadian cities, with populations of 52,100 and 40,310 respectively; however, the Aboriginal population represented only five percent of the total population in Edmonton and two percent in Vancouver. In Winnipeg, the Aboriginal population is also much younger and growing at a faster pace than the city's overall population. In 2006, the median age of the Aboriginal population in Winnipeg was 26 years, compared to 40 years for the non-Aboriginal population. Between 2001 and 2006,

4 Friendship centre catchment areas include the CSD in which a friendship centre is located, plus any neighbouring CSDs that share a border with it for high population density southern regions. In northern and low-density regions, catchment areas are defined by a 50-kilometer radius from the friendship centre. 
Winnipeg's Aboriginal population grew by 22 percent, compared with only three percent growth for the city's total population (Statistics Canada 2007a 2010).

Despite some socioeconomic improvements over time (Siggner and Costa 2005), Aboriginal people living in Winnipeg still face a number of challenges. For instance, in 2006, Winnipeg's Aboriginal population was more likely not to have finished high school, more likely to be unemployed, and more likely to live in dwellings that were crowded or in need of major repair compared to their non-Aboriginal counterparts. Full time/full year Aboriginal workers were also earning less than their non-Aboriginal counterparts (Statistics Canada 2010).

About 60 percent of Winnipeg's Aboriginal population identified as Métis in 2006, while 38 percent identified as First Nations. The majority ( 87 percent) of those who identified as First Nations reported being a Treaty Indian or a registered Indian as defined by the Indian Act of Canada (Statistics Canada 2010). Because previous work on CWB has focused on First Nations communities (O'Sullivan 2011) - that is, the population living on reserves and because the majority of the on-reserve population have Registered Indian status, this study will focus on Winnipeg's Registered Indian population.

\section{Analyses and Research Questions}

First, a series of descriptive analyses focusing on average CWB scores and gaps over time will address the following research questions: 1) How did the socioeconomic well-being of Winnipeg's Registered Indian and non-Aboriginal populations change between 1996 and 2006? 2) Which CWB components show the greatest improvements or challenges? 3) How have the gaps in CWB scores and component scores between the Registered Indian and the non-Aboriginal populations in Winnipeg changed during this ten-year period?

Second, spatial analyses were made to represent CWB scores and CWB disparities within specific areas in Winnipeg visually. The use of a smaller geographic unit such as census tracts instead of CSDs or friendship centre catchment areas allows for the analysis of CWB at the "neighbourhood" level.5 A series of maps were created using a Geographic Information System (GIS) to address the following questions: 1) How are CWB scores for Registered Indians and non-Aboriginals distributed across Winnipeg's census tracts? 2) Can we identify specific census tracts in Winnipeg where CWB disparities are greatest?

Monitoring CWB trends over time is useful to understanding a population's past and current socioeconomic conditions, as well as in helping to plan and ensure its future wellbeing. This study will provide information on CWB levels among Winnipeg's Registered Indian population, and whether and where disparities with the non-Aboriginal population exist. Through a series of maps, this study will also help identify specific areas in Winnipeg where socioeconomic differences are largest and those where differences are smaller.

5 It should be noted that census tract boundaries do not necessarily respect other municipal boundaries such as neighbourhoods. Census tracts are best used as proxies for neighbourhoods or neighbourhood clusters. 


\section{Methodology}

\section{Data Source}

The data source for this study is the Canadian Census of Population. Data from the 1996, 2001, and 2006 censuses were extracted. Individual-level census microdata (longform 20 percent sample data) were used to identify two populations living in Winnipeg: Registered Indians and non-Aboriginals. The term Registered Indians (also referred to as "status Indians") refers to those persons registered under the Indian Act, with or without membership in an Indian Band or a First Nation that signed a treaty with the Crown. The 1996, 2001, and 2006 censuses used comparable Registered Indian identifier questions (Statistics Canada 2007b). The term Non-Aboriginals refers to those persons who did not identify with an Aboriginal group, who were not registered under the Indian Act, and who were not members of an Indian band or First Nation.

\section{Geography}

The city of Winnipeg was examined at the census tract (CT) level. Census tracts are small and relatively stable geographic areas that are located in census metropolitan areas and census agglomerations with an urban core population of 50,000 or more. Specific rules are used to delineate census tracts: 1) CT boundaries must follow permanent and easily recognizable physical features; 2 ) The population of a CT should range between 2,500 and $8,000$, with a preferred average of 4,$000 ; 3)$ The CT should be as homogeneous as possible in terms of socioeconomic characteristics, having similar economic status and social living conditions at the time of its creation; 4) The CT's shape should be as compact as possible; and 5) CT boundaries should respect census metropolitan area, census agglomeration, and provincial boundaries. Changes to census tract boundaries are discouraged in order to maintain maximum data comparability between censuses (Statistics Canada 2008).

For every census tract in Winnipeg and for every selected census year, separate CWB scores and component scores were calculated for the Registered Indian population and the non-Aboriginal population, if each subpopulation had at least 40 individuals (as per weighted counts). If this was not the case, data were suppressed to keep within Statistics Canada's confidentiality guidelines. In every census tract with unsuppressed data for both the Registered Indian population and the non-Aboriginal population, a CWB difference score was also calculated by subtracting the non-Aboriginal CWB score from the Registered Indian CWB score. Other Aboriginal peoples (non-Status Indians, Métis, and Inuit) residing in Winnipeg were not analyzed in the present study.

\section{The CWB Index}

A CWB score is a single number that can range from a low of 0 to a high of 100 . It is composed of data on education, housing conditions, labour force activity, and income. The education component is comprised of two variables, accounting for two-thirds and one- 
third respectively of the component: 1) the proportion of a census tract's population aged 20 years and over that has obtained at least a high school certificate; and 2) the proportion of a census tract's population aged 25 years and over that has obtained a university degree at the bachelor's level or higher. The housing component is comprised of 1) housing quantity (or the proportion of the census tract population living in dwellings that contain no more than one person per room); and 2) housing quality (or the proportion of the census tract population living in dwellings that are not in need of major repairs), which are equally weighted. The labour force activity component is comprised of 1) labour force participation (or the proportion of the census tract population aged 20 to 65 that was involved in the labour force in the week prior to census day); and 2) employment (or the percentage of labour force participants aged 20 to 65 that was employed in the week prior to census day), which are equally weighted.

Calculations of the education, housing, and labour-force activity components of the CWB Index for our two subpopulations (i.e. the Registered Indian and the non-Aboriginal populations) were made as per established methodology to calculate CWB at the CSD level (O'Sullivan 2011). Calculating the income component at the census tract level (which, in the basic CWB calculation, is simply per-capita income) required some adaptation in order to account for the fact that many income earners share their incomes with dependents and that many Aboriginal individuals have non-Aboriginal family members. For this study, the income component was thus defined in terms of economic family income. Therefore, total economic family income was first divided among economic family members; every dollar of income received by economic family members was then divided by the total (Registered Indian or non-Aboriginal) census tract population to create per capita income for each subpopulation. The remaining income calculation steps proceeded as per established methodology.

\section{Data Limitations}

Some data limitations need to be acknowledged at this point. One limitation is consistency in census items over time. For example, census questions relating to education underwent major changes between 2001 and 2006. Information on the concept of "years of schooling" that was available prior to 2006 has been changed to focus on high school completion. As well, the 2006 Census provided a separate question for each level of educational attainment, rather than including all levels of education as part of a single question, as had been done previously. Data quality reports have shown that the university categories at the bachelor's level and above are comparable with previous censuses. However, underreporting of high school completions in censuses prior to 2006 has affected data on high school graduation. Therefore, when making historical comparisons, researchers should be aware that changes in high school completion rates from 2001 to 2006 may be an artifact of changes to the education module, and should be interpreted with caution (Statistics Canada 2009).

Even though CWB scores were suppressed if the Registered Indian or the non-Aboriginal

census tract population was smaller than 40 individuals, some census tracts nevertheless 
had relatively small Registered Indian sample sizes. Scores based on small samples may be less reliable. In addition, CWB scores over time can be influenced by changes in census tract boundaries from one census to the next. The extent to which boundary changes affect the average scores of different populations is unknown; however, census tracts are known to be relatively stable geographic areas.

\section{Results}

Community Well-Being in Winnipeg, 1996 to 2006

To provide context for our findings, we first look at Winnipeg's overall profile as per CWB Index data at the CSD level (AANDC 2010). These data show that overall, CWB scores in Winnipeg have tended to improve over time: from 77 in 1996 to 82 in 2006. Housing is the component in Winnipeg with the highest scores, at 94 in both 1996 and 2006. Labour force activity scores have remained relatively stable at 86 in 1996 and 88 in 2006, while income scores went from 80 to 86 in the same ten-year period. Consistent with what can be observed nationally (O'Sullivan 2011), education is the component in Winnipeg that has the lowest scores in all years investigated; at the same time, it is the component that showed the largest improvement over time - from 49 in 1996 to 61 in 2006.

We now describe and compare the CWB scores of two population groups - the Registered Indian and the non-Aboriginal populations - computed at the census tract level of geography in Winnipeg's urban core ${ }^{6}$ (Appendix Table 1). Figure 1 shows average CWB scores and component scores for the Registered Indian and the non-Aboriginal populations living in Winnipeg, from 1996 to 2006, calculated at the census tract level of geography. Looking at the overall pattern, non-Aboriginal individuals residing in Winnipeg have higher levels of socioeconomic well-being than their Registered Indian counterparts. Indeed, scores for the non-Aboriginal population (dotted lines) are systematically higher than scores for the Registered Indian population (full lines) at every census year examined.

Turning to trends over time, it can be seen that overall CWB scores have improved from 1996 to 2006, both for the Registered Indian and the non-Aboriginal populations. Gains over time were more pronounced for Registered Indians (from 59 in 1996 to 69 in 2006) compared to their non-Aboriginal counterparts (from 77 to 82 in the same ten-year period). Reflecting trends at the CSD level, housing is the component with the highest scores for both the Registered Indian and the non-Aboriginal populations. Housing scores also appear to be relatively stable over time for both populations. Labour scores have shown improvements over time for both populations, although gains were more pronounced for Registered Indians (from 65 in 1996 to 76 in 2006) compared to their non-Aboriginal counterparts (from 86 to 89 in the same time ten-year period). Similarly, income scores have improved over time for both populations, and gains were much more pronounced

6 An "urban core" is a large urban area around which a CMA or a CA is delineated. The urban core must have a population (based on the previous census) of at least 50,000 persons in the case of a CMA, or at least 10,000 persons in the case of a CA. 
for the Registered Indian population (from 50 in 1996 to 63 in 2006) than for the nonAboriginal population (from 79 to 85 in the same time ten-year period). Education is the component with the lowest scores for both the Registered Indian and the non-Aboriginal populations. At the same time, however, education is the component that showed the greatest improvements over time for both populations: from 34 in 1996 to 48 in 2006 for Registered Indians, and from 48 to 61 for non-Aboriginals.

FIGURE 1: Average CWB census tract scores, Winnipeg urban area, Registered Indian and non-Aboriginal populations, 1996, 2001 and 2006
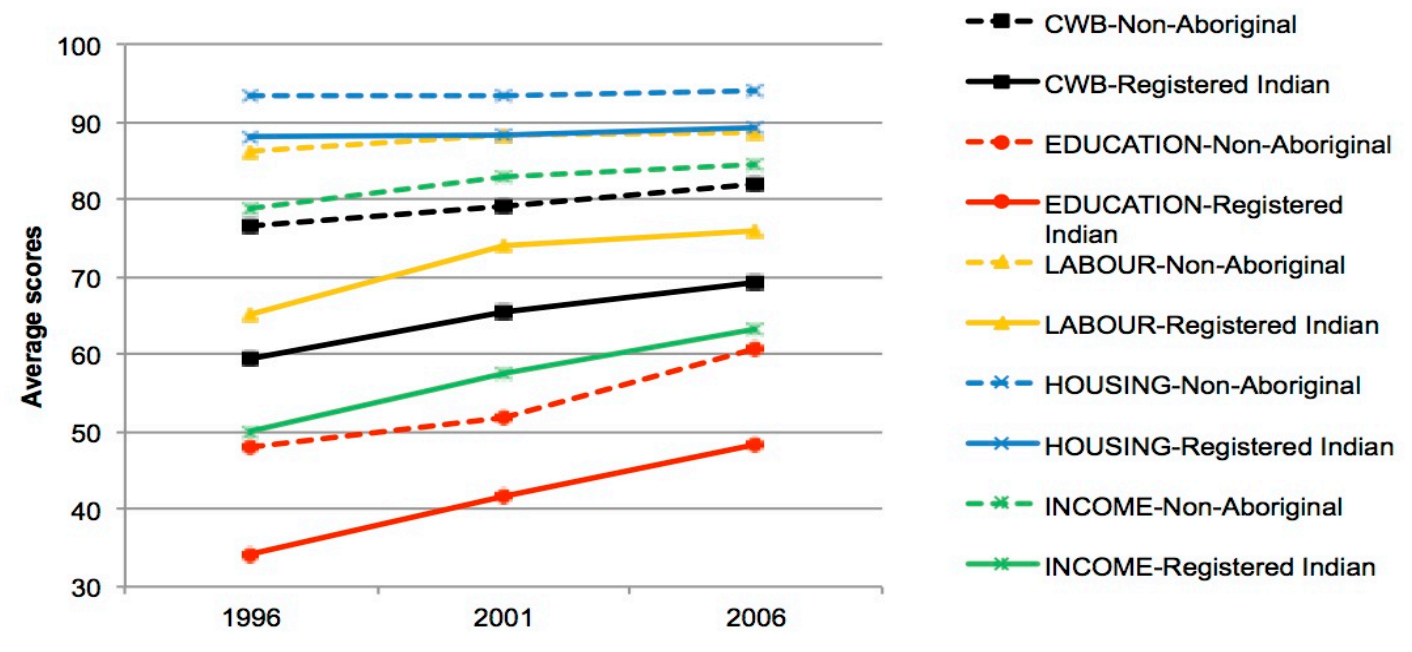

Source: 1996, 2001 and 2006 Census of Population

Figure 2 divides the education component into two subcomponents: "high school plus" (or the proportion with at least a high school diploma), and "university" (or the proportion with at least a bachelor's degree). The previously observed improvements over time in the education component appear to be primarily due to increases in high school completion rates. ${ }^{7}$ The attainment of a university degree is clearly an area in which challenges are the greatest, both for the Registered Indian and the non-Aboriginal populations living in Winnipeg.

We next examine gaps over time. Figures 3 and 4 show the distribution of average CWB scores for the Registered Indian and the non-Aboriginal populations for census years 1996 and 2006 at the census tract level of geography. In 1996 (Figure 3), the gap between the Registered Indian and the non-Aboriginal populations in Winnipeg is apparent, with the latter concentrated at the high end of the CWB range, and the former at the lower end. Indeed, nearly half (48 percent) of the Registered Indian population occupied the lower

7 Some of this increase may be attributable to changes to the 2006 Census education module, and should be interpreted with caution. 
half of the CWB Index range (between 30 and 60), 36 percent fell between 60 and 70, 16 percent between 70 and 80 , and one percent between 80 and 90 . In comparison, the lowest non-Aboriginal population CWB scores (14 percent) fell between 60 and 70, 53 percent fell between 70 and 80, 32 percent fell between 80 and 90, and one percent fell between 90 and 100 .

FIGURE 2: Average Education census tract scores, Winnipeg urban area, Registered Indian and non-Aboriginal populations, 1996, 2001 and 2006

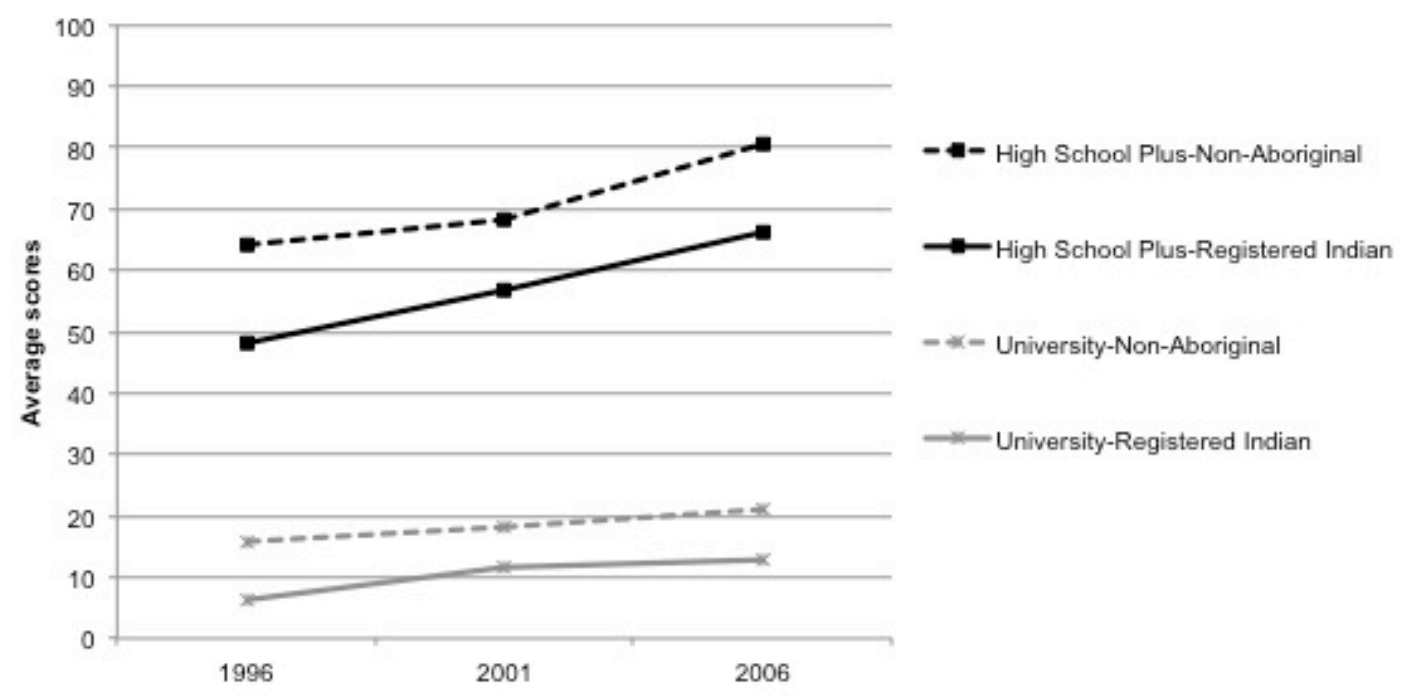

Source: 1996, 2001 and 2006 Census of Population

Data for 2006 (Figure 4) still show a CWB gap between the Registered Indian and the non-Aboriginal populations, although evidence of improved CWB scores can be seen for both populations. Indeed, about 19 percent of the Registered Indian population occupied the lower half of the index range (between 30 and 60), 27 percent fell in the 60-to-70 range, 44 percent between 70 and 80 , and 10 percent between 80 and 90 . In comparison, the lowest non-Aboriginal CWB scores (two percent) fell between 60 and 70, 30 percent fell between 70 and 80, 63 percent between 80 and 90, and six percent between 90 and 100 . 
FIGURE 3: Average CWB census tract scores distribution, Winnipeg urban area, Registered Indian and non-Aboriginal populations, 1996

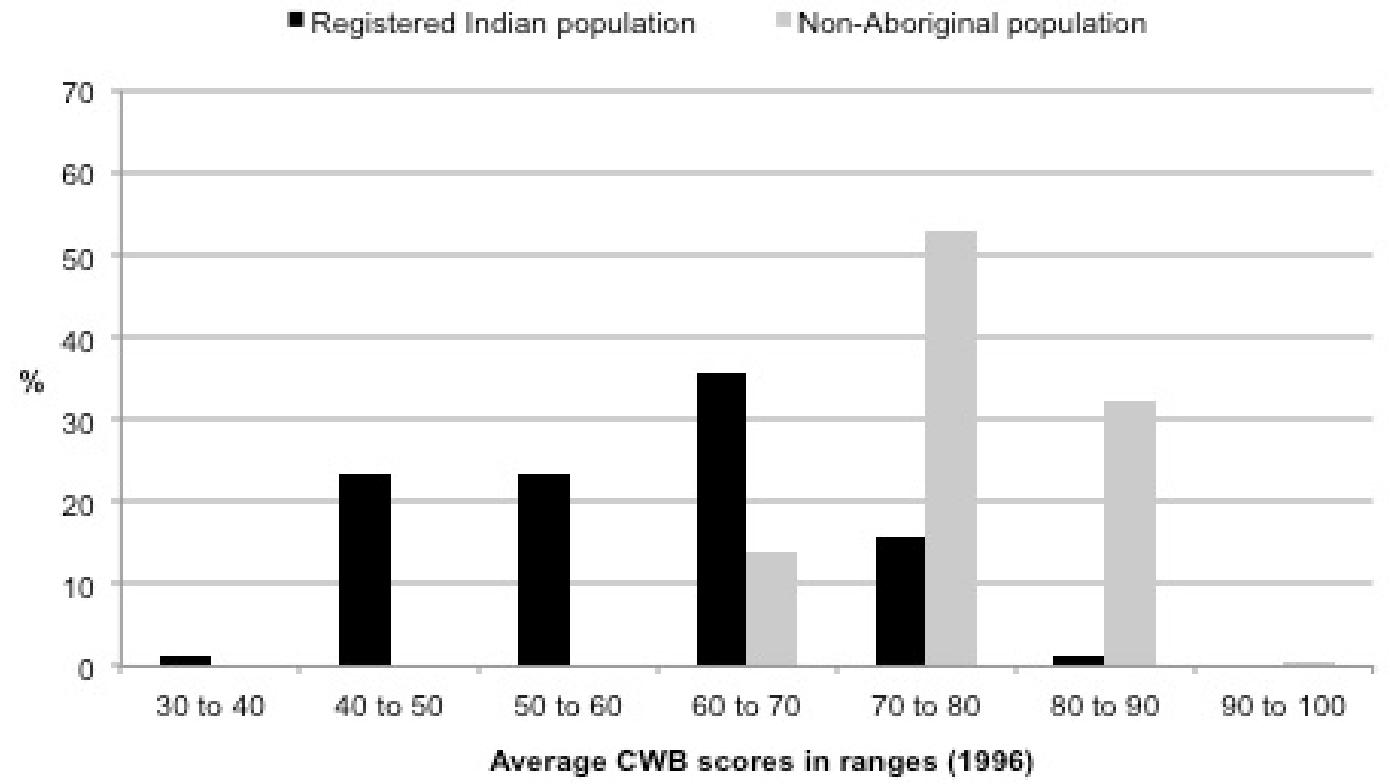

Source: 1996 Census of Population

FIGURE 4: Average CWB census tract scores distribution, Winnipeg urban area, Registered Indian and non-Aboriginal populations, 2006

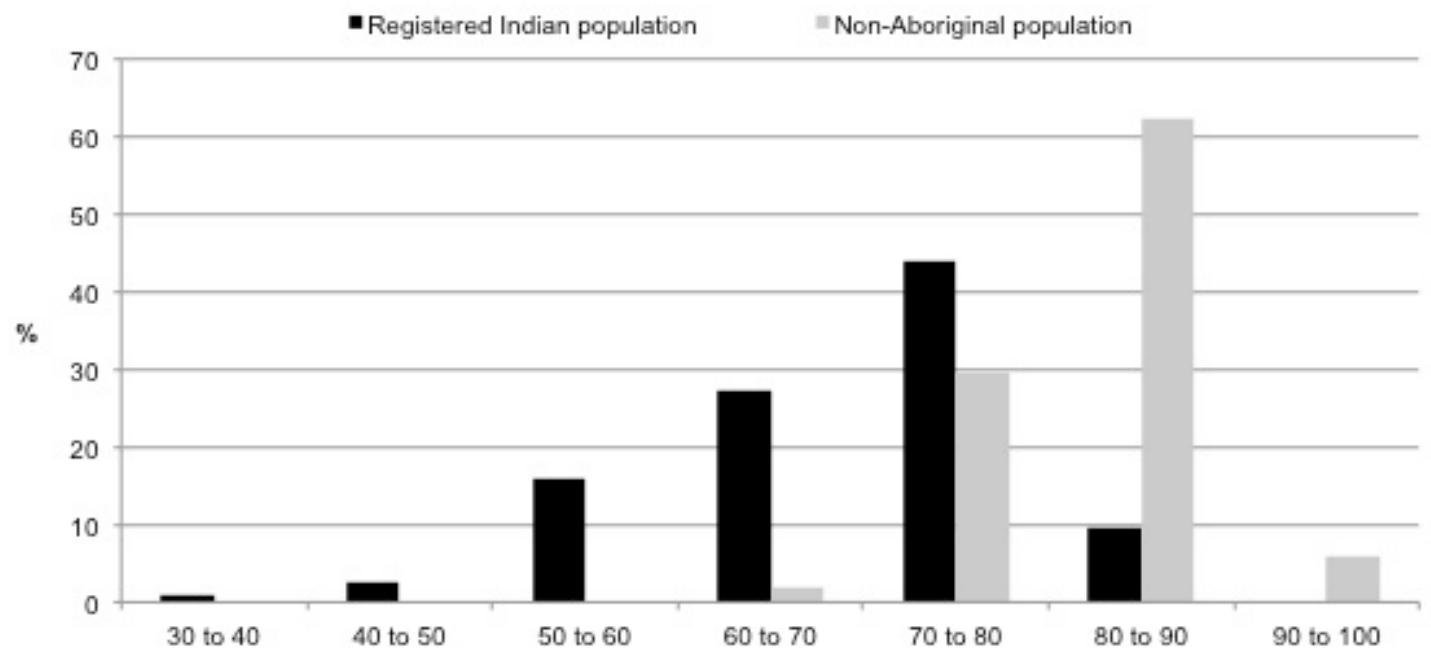

Average CWB scores in ranges (2006)

Source: 2006 Census of Population 
Figure 5 shows the net difference between average CWB scores and component scores for the Registered Indian and the non-Aboriginal populations residing in Winnipeg. All data points are negative, reflecting the fact that Registered Indians systematically score lower than non-Aboriginals on the CWB Index. In terms of overall CWB, there was a reduction in the gap between Winnipeg's Registered Indian and non-Aboriginal populations from 1996 to 2001, followed by another slight reduction from 2001 to 2006. Turning to education, there was a reduction in the gap between Registered Indians and non-Aboriginals from 1996 to 2001. However, this was followed by an increase in the gap between these populations from 2001 to 2006, bringing it nearly back to the 1996 level. Changes to the education questions in the 2006 Census may be responsible for the increase in the well-being gap between Registered Indians and non-Aboriginals during that period, and should be interpreted with caution. As for labour, there was an important reduction in the gap from 1996 to 2001, followed by another slight reduction from 2001 to 2006 . Overall, labour force activity is the component with the largest decrease in disparity between the Registered Indian and the non-Aboriginal populations in the examined ten-year period. Housing is clearly the component showing the smallest gap between Winnipeg's Registered Indian and non-Aboriginal populations. In 2006, these two populations were almost on par with each other, with less than a five-point difference in their respective scores. Despite a steady reduction in the gap over the examined ten-year period, income is by far the component showing the largest disparity between Winnipeg's Registered Indian and nonAboriginal populations: in 2006, there remained more than a 20-point difference between these two populations' scores.

FIGURE 5: CWB difference scores, Winnipeg urban area, Registered Indian and nonAboriginal populations, 1996, 2001 and 2006

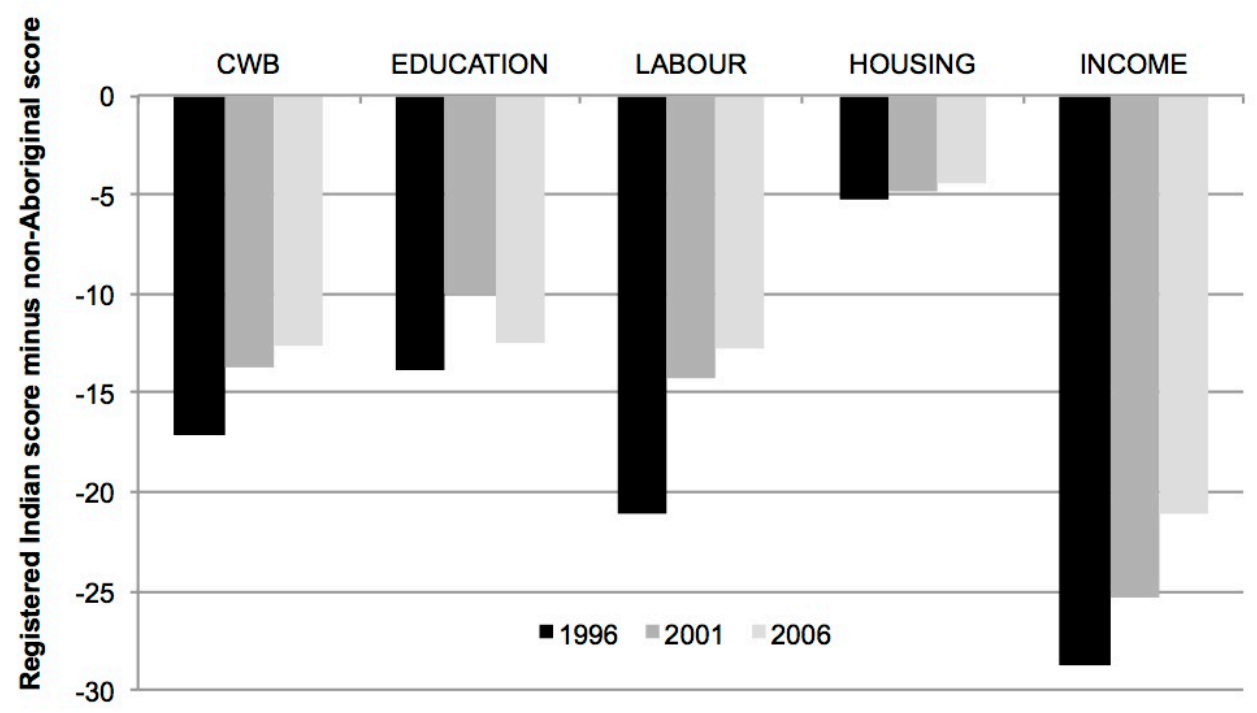

Source: 1996, 2001 and 2006 Census of Population 


\section{The Spatial Distribution of Community Well-Being in Winnipeg, 2006}

We now turn to the examination of CWB within Winnipeg's specific census tracts (CTs) for the 2006 census year. The research questions addressed in this section are:

1. How are CWB scores for Registered Indians and non-Aboriginals distributed across Winnipeg's census tracts? and

2. Can we identify specific census tracts in Winnipeg where CWB disparities are greatest?

To answer these questions visually, four maps were created. Map 1 illustrates the spatial distribution of the proportion of Registered Indians by census tract, whereby the darkest CTs represent the highest proportions. Maps 2 and 3 show the spatial distribution of average CWB scores by census tract for the Registered Indian population and the non-Aboriginal population, respectively, whereby the darkest CTs represent the lowest CWB scores. Map 4 shows the spatial distribution of CWB difference scores (Registered Indian population score minus non-Aboriginal population score). In this map, the darkest CTs represent areas in which the CWB difference scores are the largest, while the lightest CTs represent areas in which Registered Indians have equal or higher average CWB scores compared to their non-Aboriginal counterparts. Census tract boundaries do not necessarily respect municipal boundaries such as neighbourhoods. Census tracts are best used as proxies for neighbourhoods or neighbourhood clusters. ${ }^{8}$

Map 1 shows that Registered Indians are present in almost all of Winnipeg's census tracts, albeit to varying degrees. Consistent with the results of previous work for Winnipeg's North American Indian 1996 ancestry population (Maxim, Keane and White 2003), the Registered Indian population demonstrates a fair degree of concentration and centralization, as it tends to be proportionally more numerous in the CTs that are located inside Winnipeg's Downtown area and in the North End. In one CT located in the North End, Registered Indians represent more than 35 percent of that CT's total population.

Map 2 shows a clustering of census tracts (CTs) Downtown and in the North End in which Registered Indians have relatively low average CWB scores (i.e. the darker CTs with scores ranging from 1 to 49 and from 50 to 59). This clustering indicates that the lowest CWB scores for Registered Indians seem to be concentrated in a certain number of CTs. Some of these lower-scoring areas also tend to be the ones in which Registered Indians are proportionally more numerous. These findings are similar to other research that has shown a clustering of lower-income Aboriginal Dissemination Areas ${ }^{9}$ in the North of Winnipeg (Peters, Oliver and Carrière 2012), and that has indicated that areas characterized by lower CWB scores also tend to have higher proportions of Aboriginal-identity residents (Clatworthy and Peters 2011).

8 Winnipeg's census tract boundaries may be superimposed on Winnipeg's neighbourhood boundaries in order to give a visual approximation of which neighbourhoods are covered by which census tract. For this purpose, the following publicly available map can be consulted: http://winnipeg.ca/Census/2006/City\%20 of\%20Winnipeg/Downtown\%20Winnipeg/Downtown\%20Map/Winnipeg\%20Downtown\%20Zoning\%20 Bylaw\%20Map\%20-\%20Labeled.pdf.

9 Dissemination Areas are the lowest geographical level (with 400 to 700 residents) for which aggregate census information is available (Statistics Canada 2008). 
MAP 1: Proportion of Registered Indians, by Census Tract, Winnipeg urban area, 2006

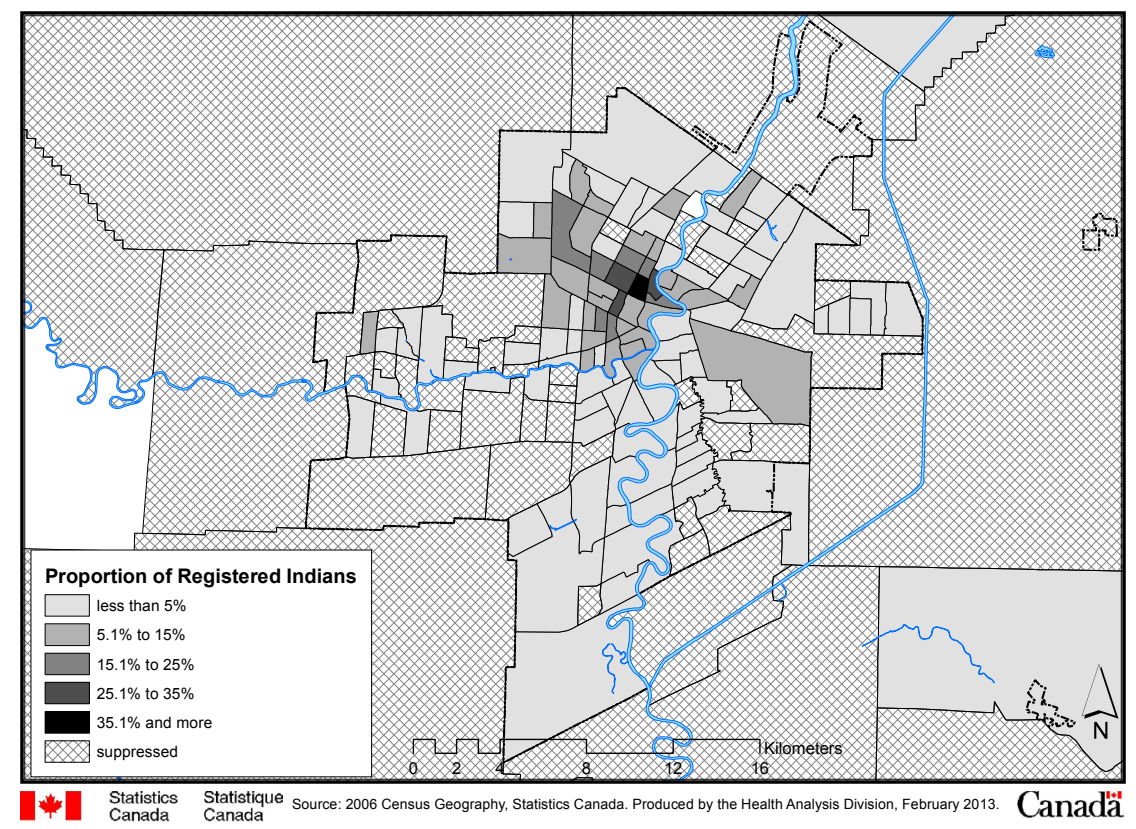

MAP 2: Community Well-Being scores, by Census Tract, Registered Indian population, Winnipeg urban area, 2006

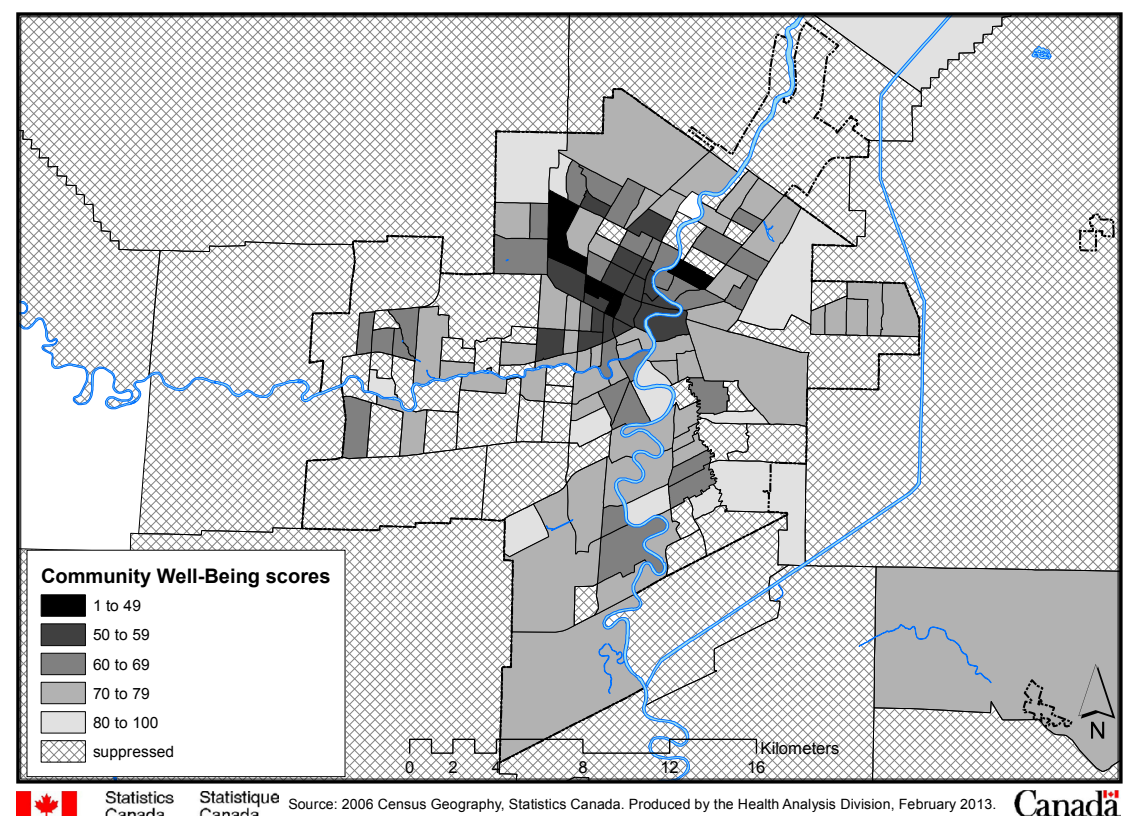

$\begin{aligned} & \text { Statistics } \\ & \text { Canada }\end{aligned}$
$\begin{aligned} & \text { Statistique Source: } 2006 \text { Census Geography, Statistics Canada. Produced by the Health Analysis Division, February 2013. Canadlä } \\ & \text { Canada }\end{aligned}$ 
There are very few CTs where Registered Indians present the highest CWB scores (i.e. the lightest CTs, with scores ranging from 80 to 100). These pockets of higher socioeconomic well-being appear to be scattered in peripheral CTs. That said, Map 2 also shows that a great many Registered Indians experience at least a moderate level of CWB in most of Winnipeg's CTs.

Map 3 shows a clustering of three CTs Downtown and in the North End where nonAboriginals have relatively lower average CWB scores; however, these lowest-scoring CTs actually have CWB values ranging from 60 to 69. The non-Aboriginal population in all other CTs in Winnipeg has average CWB scores of 70 or above.

MAP 3: Community Well-Being scores, by Census Tract, non-Aboriginal population, Winnipeg urban area, 2006

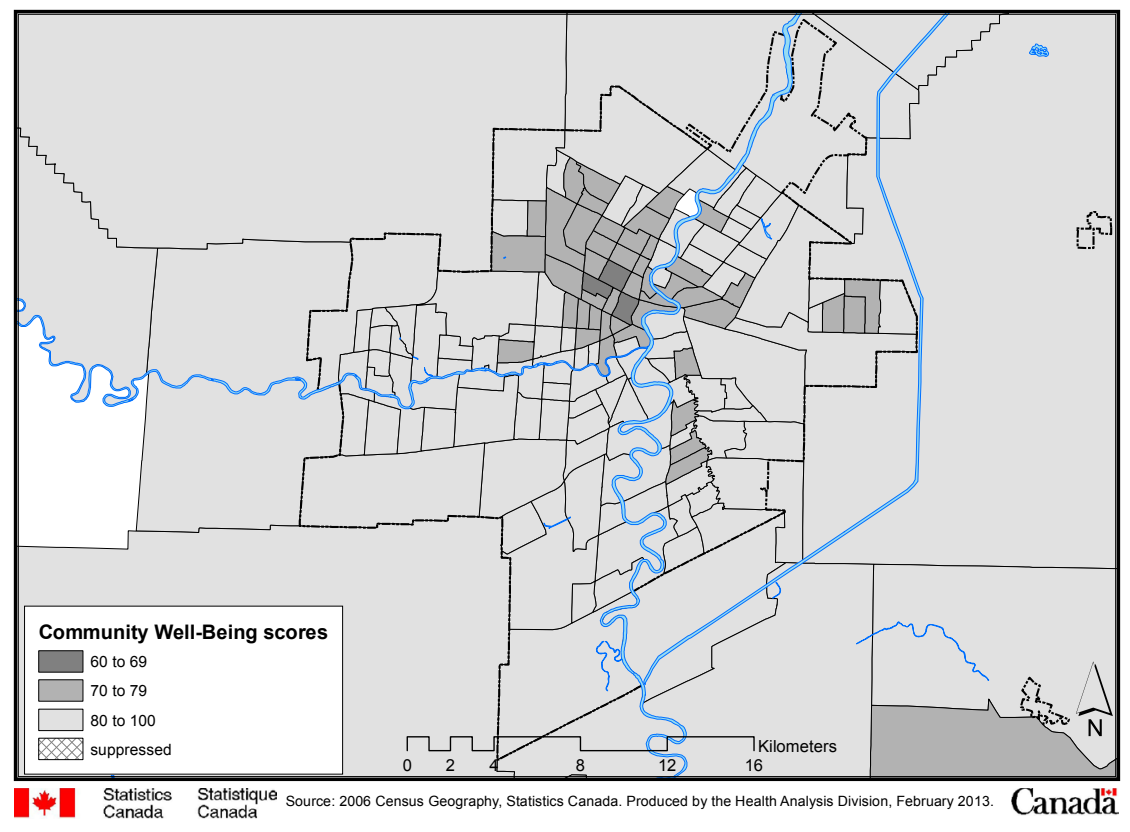

The observations drawn from Maps 2 and 3 are not unlike what is typically seen in Canada's urban and metropolitan centres, where areas with lower socioeconomic conditions tend to be clustered, typically in a city's downtown area (Pampalon et al. 2012). The CWB disparity between Registered Indians and non-Aboriginal residents of the same census tracts is best illustrated in Map 4. On the one hand, there is only a very small number of CTs ( $\mathrm{n}=6$ or five percent of examined CTs) in which Registered Indians have equal or higher average CWB scores compared to their non-Aboriginal neighbours (i.e. the lightest CTs with zero or positive difference scores). There are also several CTs ( $\mathrm{n}=45$ or 39 percent) in which Registered Indians and non-Aboriginals have CWB scores with less than a 10-point difference between them. These "lower-disparity" CTs tend to be located in peripheral neighbourhoods. On the other hand, several CTs in Winnipeg present a 10-to- 
19-point difference in CWB scores between Registered Indians and their non-Aboriginal neighbours ( $n=48$ or 42 percent). Quite a few CTs ( $n=15$ or 13 percent) have CWB score differences of 20 points or more (i.e. the darkest CTs). Some (but not all) of these "higherdisparity" CTs are located Downtown and in the North End, while others can be seen in more peripheral locations.

MAP 4: Community Well-Being difference scores, by Census Tract, Winnipeg urban area, 2006

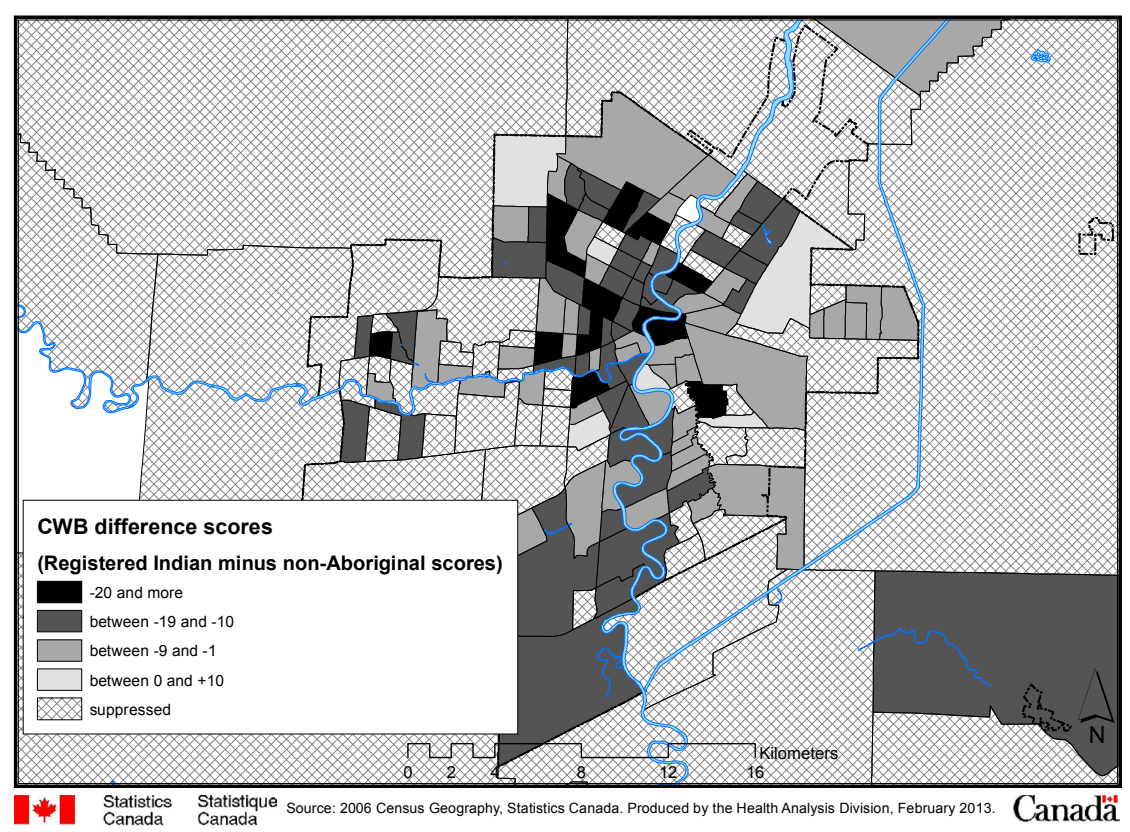

\section{Discussion}

The purpose of the present study was to examine an application of the Community WellBeing (CWB) Index by directly comparing the socioeconomic well-being of Winnipeg's Registered Indian and non-Aboriginal populations over time and among different census tracts -a proxy for neighbourhoods or neighbourhood clusters - and to pair this analysis with spatial data.

Findings from our descriptive trend analyses showed that between 1996 and 2006, both Registered Indians and non-Aboriginal individuals residing in Winnipeg saw improvements in their CWB scores. Housing was the component with the highest scores and the greatest parity between the two populations studied, while education - especially university attainment - was the component with the lowest scores for both populations. These improvements notwithstanding, differences between Winnipeg's Registered Indian and non-Aboriginal populations still existed in 2006, especially with regards to income.

Findings from our spatial analysis of the 2006 Census further revealed that some census tracts in Winnipeg presented a very large difference in CWB scores between Registered 
Indians and non-Aboriginals, while others did not. Some (but not all) of these "higherdisparity" CTs were located inside the city's Downtown area and in the North End-where higher proportions of Registered Indian residents were also observed.

It is important to keep in mind that findings from this study's spatial analysis could reflect a "neighbourhood" effect, rather than a "population" effect. A neighbourhood effect would occur if Registered Indians moved to other, more affluent neighbourhoods as they improved their personal socioeconomic conditions (Maxim et al. 2003). The present spatial analysis did not capture such mobility patterns. In addition, an individual's socioeconomic status cannot be inferred from his/her census tract's average CWB score, because more affluent individuals can live in disadvantaged areas, and vice versa. Thus, the mapping of average census tract CWB scores should be used to inform area-based, not individualbased, policies and programs (Salmond and Crampton 2012).

Another limitation exists with regards to the observed improvements in Registered Indians' CWB scores over time. Some of that improvement may originate from those people in Winnipeg who changed their identity reporting from non-Aboriginal to Aboriginal on their census forms over time. This change in identity reporting can have an important impact on the measured socioeconomic characteristics of the Aboriginal population (Siggner and Costa 2005; Guimond 2003).

These limitations notwithstanding, the present study makes a contribution by demonstrating the value of using the CWB Index to look at the quality of life of different populations living in the same urban areas at a low geographic level of analysis - in this case, Winnipeg's Registered Indian population relative to their non-Aboriginal census tract neighbours. These analyses allow for the documentation of levels of disparity among specific groups in specific areas. Findings from this study can be used to inform city planning and policies, specifically with regards to targeting of resources and services.

Future research could further inform city planning by investigating additional factors that might explain why two population groups living in the same urban neighbourhoods should present such differing CWB scores. Other dimensions of population well-being, measured by the 2006 Census of Population and relevant to the urban Aboriginal population, could be explored to further our understanding. The "residential instability" dimension of the Canadian Marginalization Index (Can-Marg 2006; Matheson et al. 2012), for instance, could capture mobility patterns as discussed above. Residential instability includes indicators such as the proportion of the population that moved in the past five years, that is living alone, that is not married or common-law, that is living in multi-unit housing, and that does not own homes. The ethnic concentration dimension of the CanMarg could also be fruitful to explore. Indeed, CWB scores for other population groups (such as recent immigrants and visible minorities) could be compared with those of the Registered Indian and non-Aboriginal populations in order to find out whether the CWB disparity observed in the present study is unique to Winnipeg's Registered Indian population. Future research could also complement the information drawn from the Census with data from the Aboriginal Peoples Survey (APS) as well as the Canadian Community 
Health Survey (CCHS). The indicators of "well-being" included in the CWB Index pertain mainly to socioeconomic well-being, while the APS and the CCHS have a wealth of data for addressing other, equally important aspects of well-being for the urban Aboriginal population, including outcomes such as physical and mental health.

Comparing higher- and lower-disparity neighbourhoods on a number of carefully selected additional dimensions of population well-being from various data sources could enhance our understanding of the dynamics of urban Aboriginal well-being in Winnipeg, and in other urban centres - in Canada and abroad - where similar analyses could be done.

\section{Conclusion}

In conclusion, this study has illustrated the utility of the CWB Index for comparing the well-being of different population groups residing in the same urban census tracts - a proxy for neighbourhoods. Researchers and stakeholders with an interest in the well-being of urban populations may consider using this tool to track outcomes over time and to assess disparities. Specific populations living within the same area may look very different in terms of their socioeconomic well-being, and this should be a consideration for those undertaking research or developing community-level policies. Paired with spatial analysis, the CWB Index allows a better understanding of the socio-demographic and socioeconomic composition of small geographic areas within a community. This information can be better used to target needs and craft policies and programs at a local area level. 


\section{Bibliography}

Aboriginal Affairs and Northern Development Canada. 2010. 2006 Community Well-Being Database. http://www.aadnc-aandc.gc.ca/eng/1100100016649/1100100016651.

Bell. N., and M. V. Hayes. 2012. "The Vancouver Area Neighbourhood Deprivation Index (VANDIX): A Census-based Tool for Assessing Small-area Variations in Health Status." Canadian Journal of Public Health 103, no. S2: S28-S32.

Canadian Index of Wellbeing. 2012. How Are Canadians Really Doing? The 2012 CIW Report. Waterloo, Ontario: Canadian Index of Wellbeing and University of Waterloo.

Chateau, D., C. Metge, H. Prior, and R. Soodeen. 2012. "Learning from the Census: The Socio-Economic Factor Index (SEFI) and Health Outcomes in Manitoba." Canadian Journal of Public Health 103, no. S2: S23-S27.

Clatworthy, S., and E. J. Peters. 2011. "Aboriginal People and Community Well-Being OffReserve." In Urban Aboriginal Communities in Canada: Complexities, Challenges, Opportunities, edited by P. Dinsdale, J. White, and C. Hanselmann, 129-152. Toronto: Thompson Educational Publishing, Inc.

LaPointe, R., S. Senécal, and E. Guimond. 2009. “The Well-Being of Communities with Significant Métis Population in Canada." Canadian Issues Winter: 85-92.

Matheson, F. I., J. R. Dunn, K. L. W. Smith, R. Moineddin, and R. H. Glazier. 2012. "Development of the Canadian Marginalization Index: A New Tool for the Study of Inequality." Canadian Journal of Public Health 103, no. S2: S12-S16.

Maxim, P. S., C. Keane, and J. White. 2003. "Urban Residential Patterns of Aboriginal People in Canada." In Not Strangers in These Parts: Urban Aboriginal Peoples, edited by D. Newhouse and E. Peters, 79-91. Ottawa: Policy Research Initiative.

Newhouse, D., and E. Peters, eds. 2003. Not Strangers in These Parts: Urban Aboriginal Peoples. Ottawa: Policy Research Initiative.

O'Sullivan, E. 2011. The Community Well-Being Index (CWB): Measuring Well-Being in First Nations and Non-Aboriginal Communities, 1981-2006. Ottawa: Aboriginal Affairs and Northern Development Canada, Strategic Research and Analysis Directorate.

Pampalon, R., D. Hamel, P. Gamache, M. D. Philibert, G. Raymond, and A. Simpson. 2012. "An Area-Based Material and Social Deprivation Index for Public Health in Québec and Canada." Canadian Journal of Public Health 103, no. S2: S17-S22.

Peters, P. A., L. N. Oliver, and G. M. Carrière. 2012. "Geozones: An Area-Based Method for Analysis of Health Outcomes (Methodological Insights)." Health Reports 23(1). Ottawa: Statistics Canada Catalogue no. 82-003-XPE.

Salmond, C. E., and P. Crampton. 2012. "Development of New Zealand's Deprivation Index (NZDep) and Its Uptake as a National Policy Tool." Canadian Journal of Public Health 103, no. S2: S7-S11.

Senécal, S., E. O'Sullivan, E. Guimond, and S. Uppal. 2007. "Applying the Community WellBeing Index and the Human Development Index to Inuit in Canada." In Aboriginal Well-Being: Canada's Continuing Challenge, edited by J. P. White, D. Beavon, and N. Spence, 149-172. Toronto: Thompson Educational Publishing, Inc. 
Siggner, A. J., and Costa, R. 2005. Aboriginal Conditions in Census Metropolitan Areas, 1981-2001. Ottawa: Statistics Canada Catalogue no. 89-613-MIE - No. 008.

Statistics Canada. 2007a. "Winnipeg, Manitoba (Code602) (table). 2006 Community Profiles. 2006 Census.” Ottawa: Statistics Canada Catalogue no. 92-591-XWE. Released March 13, 2007, accessed February 4, 2013, http://www12.statcan.ca/censusrecensement/2006/dp-pd/prof/92-591/index.cfm?Lang=E.

Statistics Canada. 2007b. How Statistics Canada identifies Aboriginal peoples. Ottawa: Statistics Canada Catalogue no. 12-592-XIE.

Statistics Canada. 2008. "2006 Census Dictionary." Ottawa: Statistics Canada Catalogue no. 92-566-XWE. February 14, accessed October 10, 2013, http://www12.statcan.gc.ca/ census-recensement/2006/ref/dict/index-eng.cfm.

Statistics Canada. 2009. "Education Reference Guide, 2006 Census." Ottawa: Statistics Canada Catalogue no. 97-560-GWE2006003. November 10, accessed March 25, 2013, http://www12.statcan.gc.ca/census-recensement/2006/ref/rp-guides/ education-eng.cfm

Statistics Canada. 2010. “2006 Aboriginal Population Profiles for Selected Cities and Communities." Ottawa: Statistics Canada Catalogue no. 89-638-X.

White, J. P., D. Beavon, and N. Spence, eds. 2007. Aboriginal Well-Being: Canada's Continuing Challenge. Toronto: Thompson Educational Publishing, Inc. 


\section{List of Tables}

Appendix Table 1. Average Community Well-Being (CWB) census tract scores and difference scores, Registered Indian and non-Aboriginal populations, Winnipeg urban area, 1996, 2001, and 2006

\section{List of Figures}

Figure 1. Average CWB census tract scores, Winnipeg urban area, Registered Indian and non-Aboriginal populations, 1996, 2001 and 2006

Figure 2. Average Education census tract scores, Winnipeg urban area, Registered Indian and non-Aboriginal populations, 1996, 2001 and 2006

Figure 3. Average CWB census tract scores distribution, Winnipeg urban area, Registered Indian and non-Aboriginal populations, 1996

Figure 4. Average CWB census tract scores distribution, Winnipeg urban area, Registered Indian and non-Aboriginal populations, 2006

Figure 5. CWB difference scores, Winnipeg urban area, Registered Indian and nonAboriginal populations, 1996, 2001 and 2006

\section{List of Maps}

Map 1. Proportion of Registered Indians, by Census Tract, Winnipeg urban area, 2006

Map 2. Community Well-Being scores, by Census Tract, Registered Indian population, Winnipeg urban area, 2006

Map 3. Community Well-Being scores, by Census Tract, non-Aboriginal population, Winnipeg urban area, 2006

Map 4. Community Well-Being difference scores, by Census Tract, Winnipeg urban area, 2006 


\section{Appendix 1}

TABLE 1: Average Community Well-Being (CWB) census tract scores and difference scores, Registered Indian and non-Aboriginal populations, Winnipeg urban area, 1996, 2001, and 2006

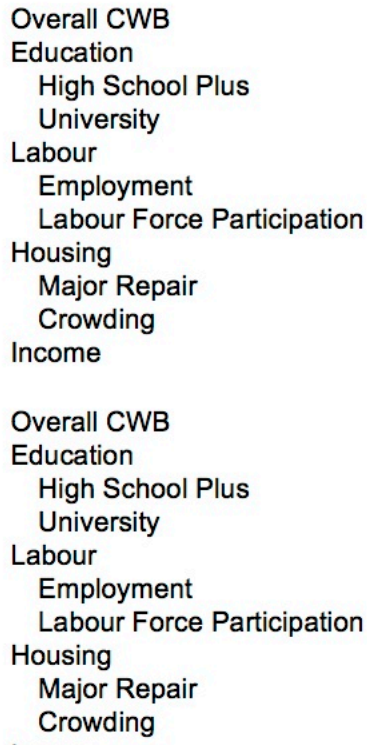

\begin{tabular}{|c|c|c|c|c|}
\hline \multicolumn{5}{|c|}{1996} \\
\hline $\begin{array}{r}\text { Number of } \\
\text { Census } \\
\text { Tracts }\end{array}$ & $\begin{array}{l}\text { Mean } \\
\text { CWB } \\
\text { score }\end{array}$ & Min & $\operatorname{Max}$ & $\begin{array}{r}\text { Difference } \\
\text { score }\end{array}$ \\
\hline \multicolumn{5}{|c|}{ Registered Indian population } \\
\hline 90 & 59 & 38 & 89 & -17 \\
\hline 90 & 34 & 2 & 83 & -14 \\
\hline 90 & 48 & 2 & 100 & -16 \\
\hline 90 & 6 & 0 & 66 & -10 \\
\hline 90 & 65 & 28 & 100 & -21 \\
\hline 90 & 72 & 18 & 100 & -21 \\
\hline 90 & 59 & 17 & 100 & -22 \\
\hline 90 & 88 & 65 & 100 & -5 \\
\hline 90 & 86 & 47 & 100 & -5 \\
\hline 90 & 91 & 40 & 100 & -6 \\
\hline 90 & 50 & 27 & 85 & -29 \\
\hline \multicolumn{5}{|c|}{ Non-Aboriginal population } \\
\hline 143 & 77 & 61 & 91 & \\
\hline 143 & 48 & 22 & 80 & \\
\hline 143 & 64 & 31 & 92 & \\
\hline 143 & 16 & 2 & 57 & \\
\hline 143 & 86 & 70 & 95 & \\
\hline 143 & 92 & 72 & 98 & \\
\hline 143 & 80 & 61 & 93 & \\
\hline 143 & 94 & 83 & 100 & \\
\hline 143 & 90 & 78 & 100 & \\
\hline 143 & 97 & 79 & 100 & \\
\hline 143 & 79 & 56 & 100 & \\
\hline
\end{tabular}

\begin{tabular}{|c|c|c|c|c|c|}
\hline & \multicolumn{5}{|c|}{2001} \\
\hline & $\begin{array}{r}\text { Number } \\
\text { of } \\
\text { Census } \\
\text { Tracts }\end{array}$ & Mean & Min & Max & $\begin{array}{r}\text { Difference } \\
\text { score } \\
\end{array}$ \\
\hline & \multicolumn{4}{|c|}{ Registered Indian population } & \\
\hline Overall CWB & 99 & 65 & 43 & 89 & -14 \\
\hline Education & 99 & 42 & 0 & 90 & -10 \\
\hline High School Plus & 99 & 57 & 0 & 100 & -12 \\
\hline University & 99 & 11 & 0 & 70 & -7 \\
\hline Labour & 99 & 74 & 46 & 100 & -14 \\
\hline Employment & 99 & 83 & 41 & 100 & -12 \\
\hline Labour Force Participation & 99 & 65 & 22 & 100 & -16 \\
\hline Housing & 99 & 89 & 61 & 100 & -5 \\
\hline Major Repair & 99 & 85 & 23 & 100 & -4 \\
\hline Crowding & 99 & 92 & 35 & 100 & -6 \\
\hline \multirow[t]{2}{*}{ Income } & 99 & 58 & 33 & 89 & -25 \\
\hline & \multicolumn{4}{|c|}{ Non-Aboriginal population } & \\
\hline Overall CWB & 150 & 79 & 63 & 92 & \\
\hline Education & 150 & 52 & 20 & 84 & \\
\hline High School Plus & 150 & 68 & 27 & 96 & \\
\hline University & 150 & 18 & 2 & 60 & \\
\hline Labour & 150 & 88 & 75 & 95 & \\
\hline Employment & 150 & 95 & 86 & 98 & \\
\hline Labour Force Participation & 150 & 82 & 58 & 94 & \\
\hline Housing & 150 & 93 & 79 & 99 & \\
\hline Major Repair & 150 & 89 & 58 & 99 & \\
\hline Crowding & 150 & 97 & 83 & 100 & \\
\hline Income & 150 & 83 & 59 & 100 & \\
\hline
\end{tabular}




\begin{tabular}{|c|c|c|c|c|c|}
\hline & \multicolumn{5}{|c|}{2006} \\
\hline & $\begin{array}{r}\text { Number } \\
\text { of } \\
\text { Census } \\
\text { Tracts }\end{array}$ & Mean & Min & Max & $\begin{array}{r}\text { Difference } \\
\text { score }\end{array}$ \\
\hline & \multicolumn{4}{|c|}{ Registered Indian population } & \\
\hline Overall CWB & 114 & 69 & 39 & 90 & -13 \\
\hline Education & 114 & 48 & 6 & 86 & -12 \\
\hline High School Plus & 114 & 66 & 9 & 100 & -15 \\
\hline University & 114 & 13 & 0 & 71 & -8 \\
\hline Labour & 114 & 76 & 16 & 100 & -13 \\
\hline Employment & 114 & 85 & 16 & 100 & -10 \\
\hline Labour Force Participation & 114 & 67 & 11 & 100 & -15 \\
\hline Housing & 114 & 90 & 64 & 100 & -5 \\
\hline Major Repair & 114 & 85 & 29 & 100 & -5 \\
\hline Crowding & 114 & 94 & 50 & 100 & -4 \\
\hline \multirow[t]{2}{*}{ Income } & 114 & 63 & 37 & 100 & -21 \\
\hline & \multicolumn{4}{|c|}{ Non-Aboriginal population } & \\
\hline Overall CWB & 152 & 82 & 67 & 93 & \\
\hline Education & 152 & 61 & 37 & 84 & \\
\hline High School Plus & 152 & 81 & 52 & 97 & \\
\hline University & 152 & 21 & 4 & 59 & \\
\hline Labour & 152 & 89 & 77 & 97 & \\
\hline Employment & 152 & 96 & 85 & 99 & \\
\hline Labour Force Participation & 152 & 82 & 67 & 95 & \\
\hline Housing & 152 & 94 & 81 & 100 & \\
\hline Major Repair & 152 & 91 & 75 & 100 & \\
\hline Crowding & 152 & 97 & 79 & 100 & \\
\hline Income & 152 & 84 & 63 & 100 & \\
\hline
\end{tabular}

Sources: Census of Population 1996, 2001, 2006 